\title{
Kualitas Batuan di Tambang Tanah Liat Sebagai Bahan Campuran Semen PT Semen Gresik Kabupaten Rembang
}

\author{
Charlotte Tiffany $^{1^{*}}$, Tri Winarno ${ }^{1}$, Jenian Marin ${ }^{1}$ \\ ${ }^{1}$ Departemen Teknik Geologi, Fakultas Teknik, Universitas Diponegoro
}

\begin{abstract}
Abstrak
Tambang batugamping diperlukan untuk memenuhi kebutuhan komponen kalsium karbonat $\left(\mathrm{CaCO}_{3}\right)$ dan tambang tanah liat diperlukan untuk memenuhi kebutuhan komponen alumina $\left(\mathrm{Al}_{2} \mathrm{O}_{3}\right)$ dan silika $\left(\mathrm{SiO}_{2}\right)$. Daerah penelitian di tambang tanah liat PT Semen Indonesia (Persero) Tbk di Kabupaten Rembang, tersusun oleh beberapa jenis litologi yang berbeda, sehingga memerlukan penelitian ini mengetahui pengaruh variasi litologi terhadap kualitas kimia batuan sebagai bahan campuran semen berdasarkan standar perusahaan. Metode yang dilakukan mencakup observasi lapangan, pengambilan sampel batuan, uji laboratorium berupa $X$-Ray Fluorescence (XRF), dan pengamatan petrografi. Tujuan dilakukanya penelitian yaitu untuk mengetahui jenis dan persebaran litologi, mengetahui persebaran kadar kimia $\left(\mathrm{Al}_{2} \mathrm{O}_{3}, \mathrm{SiO}_{2}\right.$, dan $\left.\mathrm{SO}_{3}\right)$, mengetahui kaitan jenis litologi dengan kadar kimia, dan menentukan area dengan litologi yang memenuhi standar bahan campuran semen di daerah penelitian. Lokasi penelitian tersusun oleh 4 jenis satuan litologi yang termasuk dalam Formasi Ngrayong, yaitu Satuan Batupasir Kuning, Satuan Batulanau, Satuan Batulempung, dan Satuan Batupasir Cokelat. Satuan batuan yang memenuhi standar kualitas kimia bahan campuran semen adalah Satuan Batulempung dan Satuan Batupasir Cokelat, dan satuan yang tidak memenuhi standar adalah Satuan Batulanau dan Satuan Batupasir Kuning.
\end{abstract}

Kata kunci: Batugamping; Formasi Ngrayong; Rembang; semen; tanah liat; XRF.

\begin{abstract}
Limestone is needed to fulfill lime (CaCO3) content, and clay is needed to fulfill alumina (Al2O3) and silica (SiO2) content. Research area, located at PT Semen Indonesia (Persero) Tbk clay mine in Rembang Regency, is composed of several different lithology types, so it is necessary to determine the relation of chemical quality of rock to the lithology variation. The methods conducted include field observations, X-Ray Fluorescence (XRF) test and petrographic analysis. The aim of this research is to determine lithology and its distribution, to map the distribution of chemical composition $\left(\mathrm{Al}_{2} \mathrm{O}_{3}, \mathrm{SiO}_{2}\right.$, dan $\mathrm{SO}_{3}$ ), to determine the correlation of lithology and chemical composition and map the qualified lithology for cement mixture. The research area is composed of 4 types of lithology units included in the Ngrayong Formation, namely Yellow Sandstone Units, Siltstone Units, Claystone Units, and Brown Sandstone Units. Rock units that meet the chemical quality standards of cement mixture are Claystone Units and Brown Sandstone Units, and units that do not meet the standards are Siltstone Units and Yellow Sandstone Units.
\end{abstract}

Key words: Limestone; Ngrayogn Formation; Rembang; cement; clay; XRF.

\section{PENDAHULUAN}

PT Semen Indonesia (Persero) Tbk Rembang memiliki dua tambang bahan baku semen yaitu tambang batugamping dan tambang tanah liat. Batugamping dibutuhkan untuk memenuhi salah satu komponen utama semen yaitu kapur $(\mathrm{CaO})$, sedangkan tanah liat dibutuhkan untuk memenuhi komponen alumina $\left(\mathrm{Al}_{2} \mathrm{O}_{3}\right)$ dan silika $\left(\mathrm{SiO}_{2}\right)$. Menurut Darwis (2018), tanah liat merupakan tanah berukuran lempung yang bersifat plastis dan kohesif. Menurut Shetty (2000), $\mathrm{SiO}_{2}$ merupakan senyawa berbentuk padatan dengan persentase volume sekitar 50 hingga $60 \%$ yang berguna untuk memperkokoh struktur semen, sedangkan $\mathrm{Al} 2 \mathrm{O} 3$ dibutuhkan agar semen dapat dengan mudah bereaksi terhadap air dan membentuk pasta semen.

Tambang yang dimiliki PT Semen Indonesia

\footnotetext{
*Korespondensi: charlottetiffany@ @students.undip.ac.id
} 
(Persero) Tbk tergolong baru sehingga informasi terkait kualitas bahan baku semen yang ada pada tambang tersebut masih sedikit dan data hasil eksplorasi yang dimiliki belum mendetail. Khususnya pada tambang tanah liat yang memiliki jenis litologi yang cukup bervariasi, diperlukan adanya penelitian lebih lanjut terkait kualitas sebagai bahan campuran semen yang dipengaruhi oleh perbedaan jenis litologi, sehingga didapatkan rekomendasi area penambangan sesuai standar kualitas kimia yang dibutuhkan.

Penelitian dilakukan pada area tambang terbuka tanah liat PT Semen Indonesia (Persero) Tbk di Desa Kajar, Kecamatan Gunem, Kabupaten Rembang, Jawa Tengah (Gambar 1). Tujuan dilakukanya penelitian yaitu untuk mengetahui jenis litologi serta persebarannya di area penelitian, mengetahui persebaran kadar kimia $\left(\mathrm{Al}_{2} \mathrm{O}_{3}, \quad \mathrm{SiO}_{2}\right.$, dan $\left.\mathrm{SO}_{3}\right)$ di daerah penelitian, mengetahui kaitan jenis litologi dengan kadar kimia, dan mengetahui area dengan litologi yang memenuhi standar sebagai bahan campuran semen.

\section{Geologi Regional}

Peta geologi regional area tambang PT Semen Indonesia (Persero) Tbk di Kabupaten Rembang dapat dilihat pada Gambar 2 dengan Izin Usaha Pertambangan (IUP) batugamping berada pada daerah yang tersusun oleh satu formasi, yaitu Formasi Paciran. Formasi Paciran terdiri dari satu jenis litologi, yaitu batugamping masif bersifat dolomitan, mengandung koral algae dan foraminifera (terumbu) (Firmansyah dan Dewi, 2014). IUP tanah liat dan daerah penelitian tersusun oleh satu formasi, yaitu Formasi Ngrayong. Formasi Ngrayong terdiri dari 5 jenis litologi, yaitu batupasir, serpih, batulempung, batulanau, dan batubara. Formasi Ngrayong diendapkan pada Miosen Awal sampai Miosen Tengah (Pardosi dan Solihin, 2018).

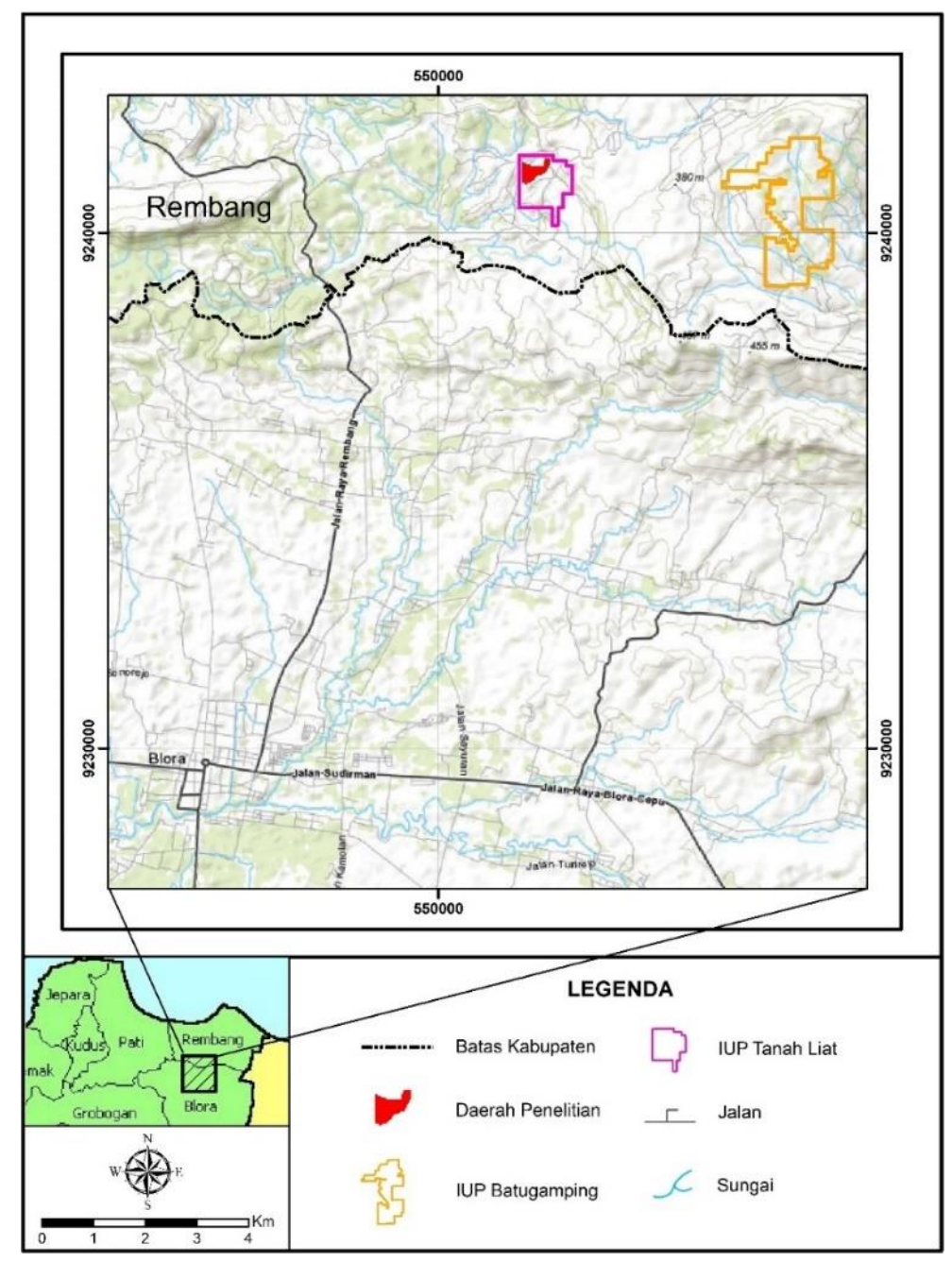

Gambar 1.1 Lokasi penelitian (PTSG, 2019) 


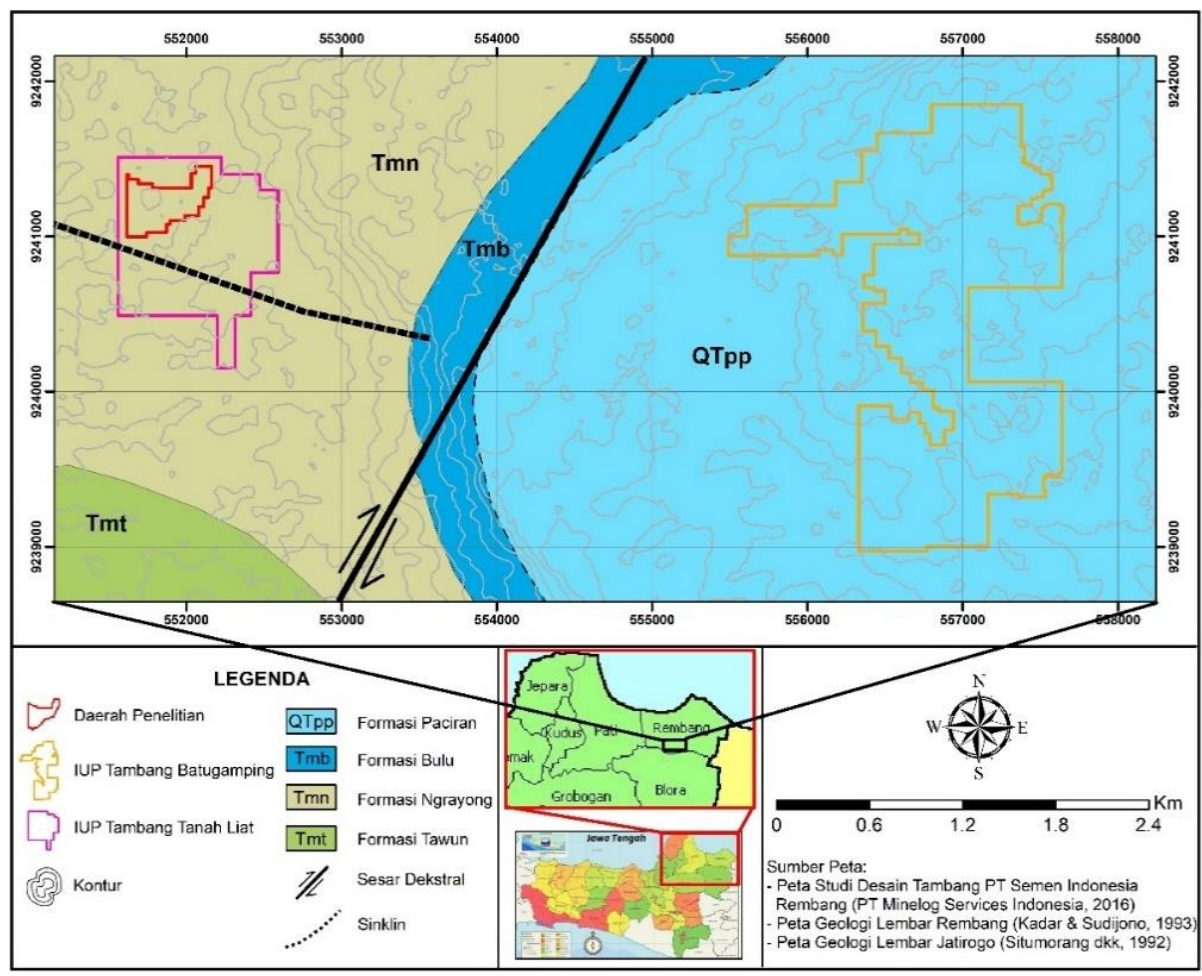

Gambar 2. Peta geologi regional daerah penelitian.

Abdillah (2012) menyebutkan bahwa terdapat 4 satuan litologi pada Formasi Ngrayong yang ditemukan di daerah Tempuran Blora. Satuan litologi tersebut yaitu batulanau sisipan pasir yang diendapkan pada fasies delta plain, batupasir sisipan lanau (terdapat sisipan material karbon) yang diendapkan pada fasies distributary mouth bar, batupasir diendapkan pada fasies backshore, dan batugamping klastik diendapkan di shallow marine.

\section{Komposisi Kimia Semen Portland}

Oksida saling berinteraksi dan membentuk senyawa yang lebih kompleks. Semen portland tersusun oleh empat senyawa kimia dasar yaitu belite, alite, aluminate, dan ferrite (Aldieb dan Ibrahim, 2010).

Belite atau dikalsium silikat (C2S), menyusun sekitar $15-30 \%$ klinker semen portland biasa. Senyawa ini terhidrasi dan mengeras secara perlahan. Sangat berperan pada penguatan semen setelah 1 minggu.

Alite atau trikalsium silikat (C3S), merupakan komponen yang paling penting, menyusun sekitar 50-70\% klinker semen portland biasa. Senyawa ini sangat cepat terhidrasi dan megeras. Sangat berperan pada initial set dan penguatan awal semen.

Aluminate atau trikalsium aluminat $(\mathrm{C} 3 \mathrm{~A})$, menyusun sekitar 5-10\% klinker semen portland biasa. Senyawa ini melepaskan panas yang banyak ketika tahap awal hidrasi, tetapi memiliki sedikit kontribusi dalam penguatan semen. Gipsum memperlambat hidrasi senyawa ini. Semen yang rendah C3A resisten terhadap sulfat.

Ferrite atau tetrakalsium aluminoferrit (C4AF), menyusun sekitar 5-15\% klinker semen portland biasa. Senyawa ini merupakan agen "fluxing" yang mengurangi temperatur bahan mentah dalam kiln dari $3000^{\circ} \mathrm{F}$ ke $2600^{\circ} \mathrm{F}$. Terhidrasi dengan cepat, namun tidak berkontribusi banyak terhadap kekuatan semen.

\section{Standar Kualitas Bahan Baku Semen}

Menurut Labahn (1983), untuk memproduksi semen diperlukan campuran bahan baku yang komposisi kimianya sesuai dengan batas-batas tertentu. Produksi semen dengan kualitas tinggi yang berkelanjutan hanya memungkinkan jika campuran bahan baku memiliki komposisi optimal. Batas nilai komposisi bahan baku dapat dilihat pada Tabel 2 yang umumnya digunakan pabrik semen. Standar komposisi kimia Semen Portland yang dikeluarkan oleh Badan Standarisasi Nasional (2004), dapat dilihat pada Tabel 2. Klasifikasi oksida yang digunakan oleh laboratorium pabrik PT Semen Gresik Rembang untuk bahan-bahan yang didapatkan dari tambang tanah liat dapat dilihat pada Tabel 3. 
Tabel 1. Standar komposisi kimia Semen Portland (Badan Standarisasi Nasional, 2004)

\begin{tabular}{lccccc}
\hline \multirow{2}{*}{ Uraian } & \multicolumn{5}{c}{ Jenis Semen Portland } \\
\cline { 2 - 6 } & I & II & III & IV & V \\
\hline SiO2 minimum & - & 20,0 & - & - & - \\
A12O3 maksimum & - & 6,0 & - & - & - \\
Fe2O3 maksimum & - & 6,0 & - & 6,5 & - \\
MgO maksimum & 6,0 & 6,0 & 6,0 & 6,0 & 6,0 \\
SO3 maksimum & & & & & \\
Jika C3A $\leq 8,0$ & 3,0 & 3,0 & 3,5 & 2,3 & 2,3 \\
Jika C3A > 8,0 & 3,5 & - & 4,5 & - & - \\
Hilang pijar, maksimum & 5,0 & 3,0 & 3,0 & 2,5 & 3,0 \\
Bagian tak larut, maksimum & 3,0 & 1,5 & 1,5 & 1,5 & 1,5 \\
C3S, maksimum & - & - & - & 35 & - \\
C2S, minimum & - & - & - & 40 & - \\
C3A, maksimum & - & 8,0 & 15 & 7 & 5 \\
C4AF + 2 C3A atau & - & - & - & - & 25 \\
C4AF + C2F maksimum & & & & & \\
\hline
\end{tabular}

Tabel 2. Batas komposisi oksida (Labahn, 1983)

\begin{tabular}{cc}
\hline Oksida & Persentase Konten (\%) \\
\hline $\mathrm{CaO}$ & $60-67$ \\
$\mathrm{SiO}_{2}$ & $18-24$ \\
$\mathrm{Al}_{2} \mathrm{O}_{3}$ & $4-8$ \\
$\mathrm{Fe}_{2} \mathrm{O}_{3}$ & $1-8$ \\
$\mathrm{MgO}^{\mathrm{NgO}}$ & $<5$ \\
Alkali $\left(\mathrm{K}_{2} \mathrm{O}, \mathrm{Na}_{2} \mathrm{O}\right)$ & $<2$ \\
$\mathrm{SO}_{3}$ & $<3$ \\
\hline
\end{tabular}

Tabel 3. Klasifikasi kadar senyawa tanah liat (PTSG, 2019)

\begin{tabular}{cc}
\hline Oksida & Persentase (\%) \\
\hline $\mathrm{Al}_{2} \mathrm{O}_{3}$ & low $<16,5<$ high \\
$\mathrm{SiO}_{2}$ & low $<65-70<$ high \\
$\mathrm{SO}_{3}$ & low $<1-2,5<$ high \\
\hline
\end{tabular}

\section{METODOLOGI}

Metode yang digunakan dalam penelitian ini yaitu observasi lapangan, uji $X$-Ray Fluorescence $(\mathrm{XRF})$, dan analisis petrografi. Pengamatan lapangan dilakukan untuk mengetahui kondisi geologi daerah penelitian yaitu jenis litologi dan penampang geologi. Lokasi stasiun pengamatan ditampilkan pada Gambar 3.

Analisis petrografi dilakukan untuk mengetahui pemerian batuan berdasarkan komposisi mineral yang teramati di bawah mikroskop polarisator. Uji XRF dilakukan untuk mengetahui kadar kimia batuan di area penelitian. Hasil uji XRF dipakai untuk membuat peta distribusi kadar kimia. Metode interpolasi yang diaplikasikan adalah kriging.

\section{HASIL}

\section{Kondisi Geologi}

Kondisi litologi di daerah penelitian telah mengalami pelapukan dengan derajat pelapukan II-III (lapuk ringan - lapuk sedang), namun di beberapa tempat masih terdapat singkapan segar yang menunjukkan kenampakan struktur sedimen dan fosil jejak. Penelitian hanya dilakukan pada area tambang yang sudah terkupas karena area IUP tambang tanah liat yang belum ditambang masih dipinjamkan ke masyarakat sekitar untuk dikelola sebagai lahan pertanian.

Pada daerah penelitian ditemukan empat jenis satuan litologi yang berbeda, yaitu Batupasir Kuning, Batulanau, Batulempung, dan Batupasir Cokelat. Hasil pengamatan lapangan berupa titik pengamatan dan jalur yang dilintasi ditunjukkan pada peta lintasan (Gambar 4.1) dan persebaran satuan batuan dapat dilihat pada Gambar 4.2.

Pada STA 21 ditemukan kontak batuan antara Batupasir Cokelat (ketebalan $3 \mathrm{~m}$ ) dan Batulempung (ketebalan $2 \mathrm{~m}$ ) yang memiliki struktur laminasi dan terdapat perselingan batupasir. Pada STA 26 ditemukan kontak batuan antara Batulempung (ketebalan $1 \mathrm{~m}$ ) dan Batulanau (ketebalan $1 \mathrm{~m}$ ) yang berwarna hitam. Pada STA 12 ditemukan Batulempung dengan tebal kurang lebih $2 \mathrm{~m}$ yang memiliki struktur laminasi dan terdapat perselingan batupasir. Pada STA 30 ditemukan kontak batuan antara Batulanau yang berwarna hitam (ketebalan $2 \mathrm{~m}$ ) dan Batupasir Kuning yang berwarna putih kekuningan (ketebalan $2 \mathrm{~m}$ ).

Satuan Batupasir Kuning terdiri dari satu litologi yaitu batupasir. Kondisi singkapan yang 
ditemukan di lapangan memiliki derajat pelapukan tingkat III (lapuk sedang). Litologi ini secara megaskopis memiliki struktur masif, tekstur berwarna kuning keputih-putihan, ukuran butir pasir sangat halus - pasir sedang, kemas tertutup, serta sortasi yang tergolong well-sorted. Sementasi batuan ini non-karbonatan.

Pengamatan petrografi sayatan tipis sampel dari Batupasir Kuning menunjukkan struktur masif, tekstur berupa ukuran butir <1/256 - 1/4 $\mathrm{mm}$, sortasi sedang, dan kemas terbuka. Dijumpai mineral kuarsa $(45 \%)$, mineral lempung $(50 \%)$, mineral opak (5\%) (Gambar 4). Berdasarkan komposisi tersebut, batuan ini termasuk Quartz Wacke (Pettijohn, 1975).
Satuan Batulanau terdiri dari 3 litologi, yaitu batulanau, batubara, dan batupasir. Kondisi singkapan yang ditemukan di lapangan memiliki derajat pelapukan tingkat II (lapuk ringan). Secara megaskopis batulanau memiliki tekstur berwarna hitam dan berukuran butir lanau. Strukturnya sebagian masif, di beberapa tempat dijumpai laminasi, serta ichnofossil berupa burrowing. Semennya non-karbonatan dan dijumpai mineral pirit baik yang terdiseminasi maupun terkonsentrasi menyelimuti nodul. Batubara dijumpai dengan ketebalan kurang lebih $5 \mathrm{~mm}$, berwarna hitam, memiliki densitas yang sangat ringan dan sangat rapuh. Batupasir dijumpaidengan ketebalan 5-10 mm, berwarna

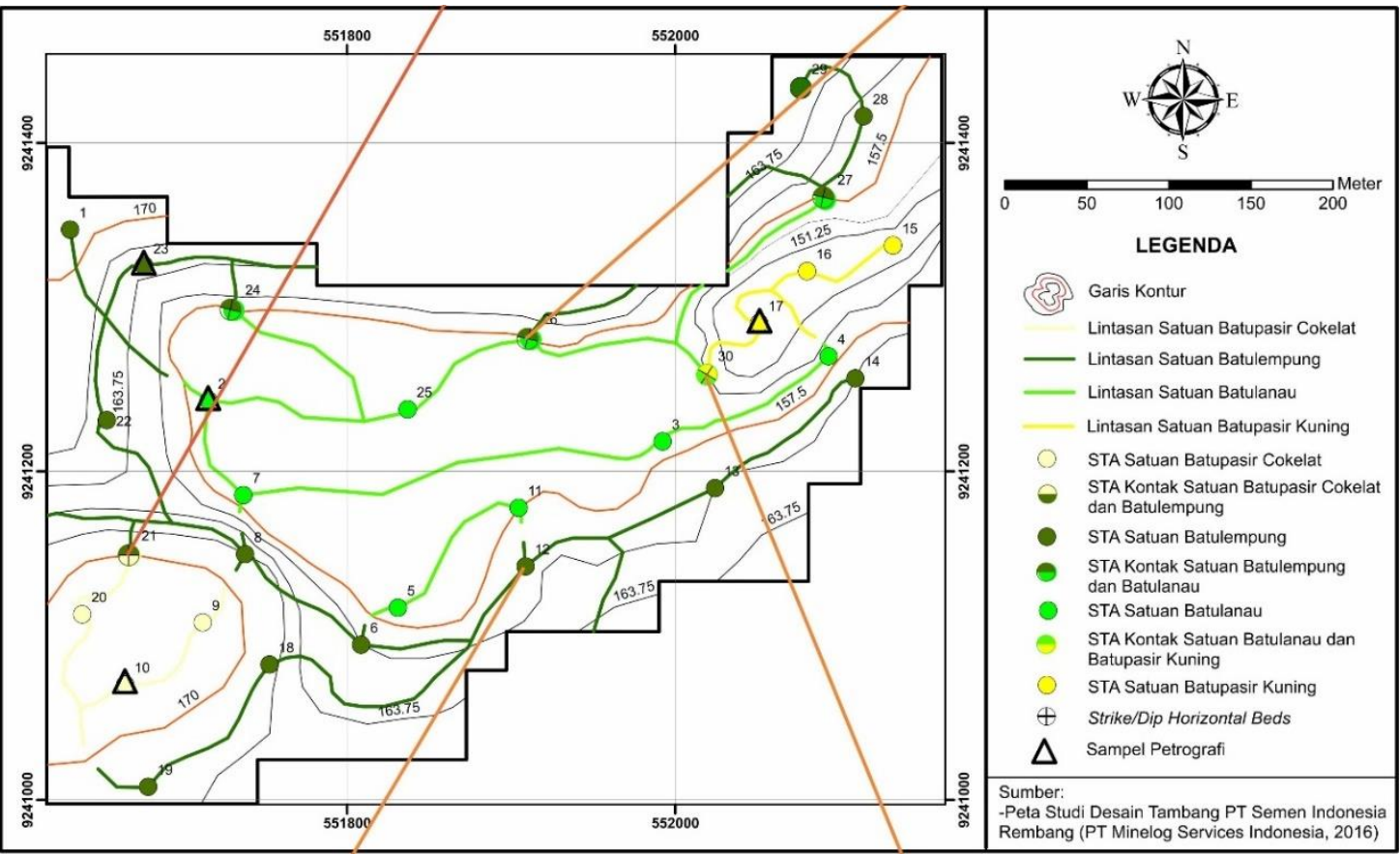

Gambar 3. Peta lokasi stasiun pengamatan

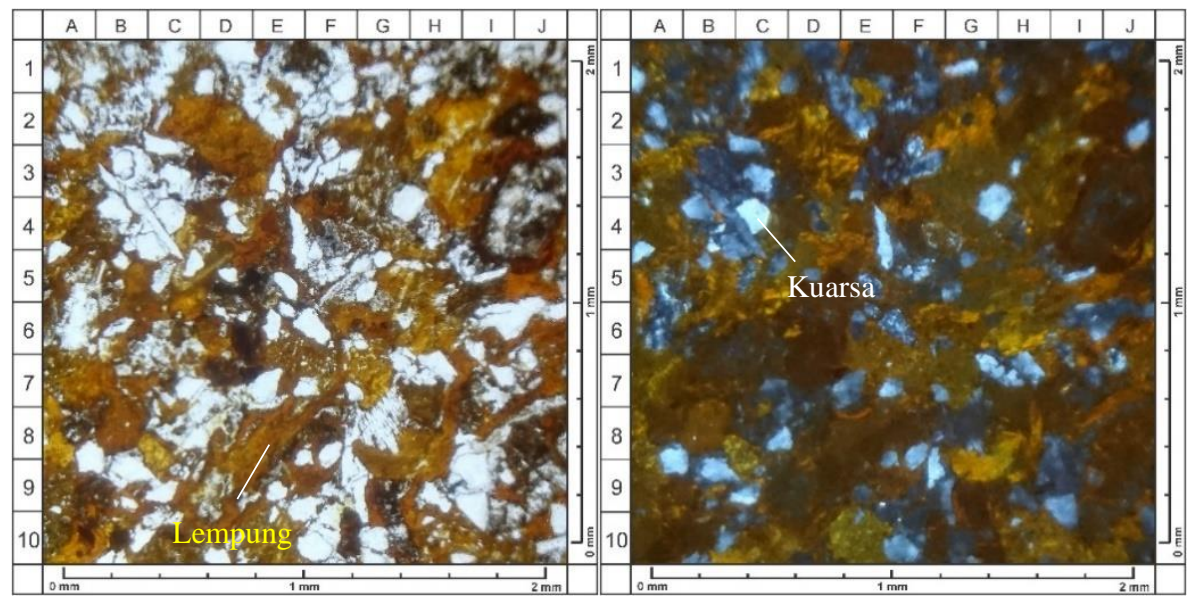

Gambar 4. Batupasir dari Satuan Batupasir Kuning di STA 17 polarisator sejajar (kiri), polarisator tegak lurus (kanan) 
abu-abu dengan ukuran butir pasir sangat halus pasir halus.

Berdasarkan pengamatan petrografi sayatan tipis batulanau, diketahui bahwa ukuran butir $<1 / 256-1 / 6 \mathrm{~mm}$, sortasi sedang, dan kemas terbuka. Dijumpai mineral kuarsa (20\%), mineral lempung (73\%), dan mineral opak (7\%) (Gambar 5). Berdasarkan komposisi tersebut, batuan ini diklasifikasikan Mudrock (Pettijohn, 1975).

Satuan Batulempung terdiri dari dua litologi yaitu batulempung dan batupasir. Kondisi singkapan yang ditemukan di lapangan memiliki derajat pelapukan tingkat III (lapuk sedang). Secara megaskopis batulempung memiliki tekstur berwarna abu-abu kemerahan dan ukuran butir lempung. Strukturnya masif dan di beberapa tempat ditemui struktur sedimen berupa laminasi. Semen batuan ini non-karbonatan. Batupasir berwarna kuning kecoklatan ditemukan dengan ketebalan 1-5 mm dengan struktur laminasi.

Hasil pengamatan petrografi batulempung menunjukkan ukuran butir $<1 / 256 \mathrm{~mm}$, sortasi baik, dan kemas tertutup. Komposisi penyusun terdiri dari kuarsa (3\%), mineral lempung (82\%), mineral opak (15\%). Berdasarkan komposisi, batuan ini termasuk Mudrock (Pettijohn, 1975).

Satuan Batupasir Cokelat terdiri dari satu litologi yaitu batupasir. Kondisi singkapan yang ditemukan di lapangan memiliki derajat pelapukan tingkat II (lapuk ringan). Litologi ini secara megaskopis memiliki struktur masif dengan tekstur berwarna cokelat keabuan, ukuran butir pasir sedang, kemas tertutup, dengan sortasi tergolong well-sorted, sementasi non-karbonatan. Pada litologi ini juga ditemukan pecahanpecahan batubara berukuran $\pm 1 \mathrm{~cm}$. Hasil pengamatan petrografi sayatan tipis batupasir dijumpai mineral kuarsa (30\%), mineral lempung (69\%), mineral opak (1\%) (Gambar 6). Berdasarkan komposisi tersebut, batuan ini termasuk Quartz Wacke (Pettijohn, 1975).

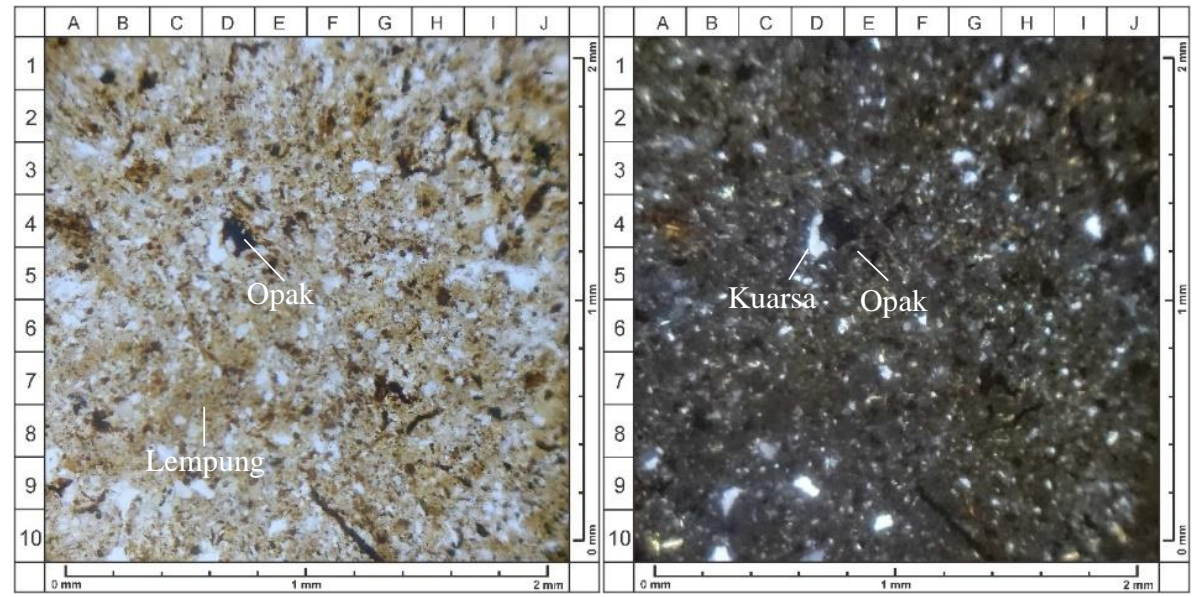

Gambar 5. Batulanau dari Satuan Batulanau di STA 2 polarisator sejajar (kiri), polarisator tegak lurus (kanan)

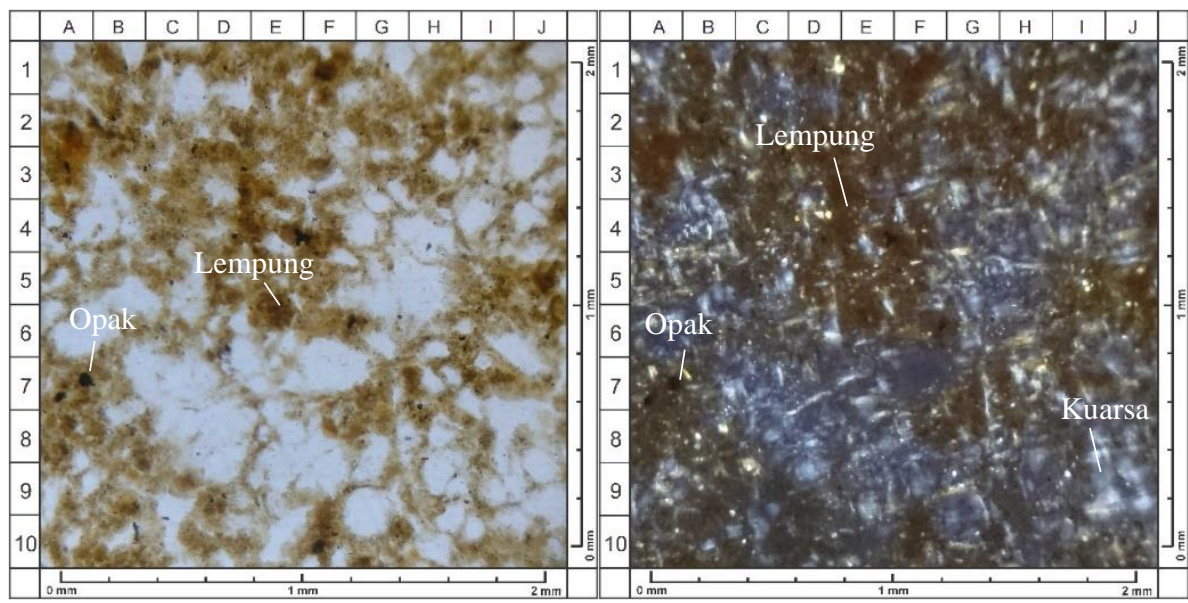

Gambar 6. Batupasir dari Satuan Batupasir Cokelat di STA 10 polarisator sejajar (kiri), polarisator tegak lurus (kanan) 


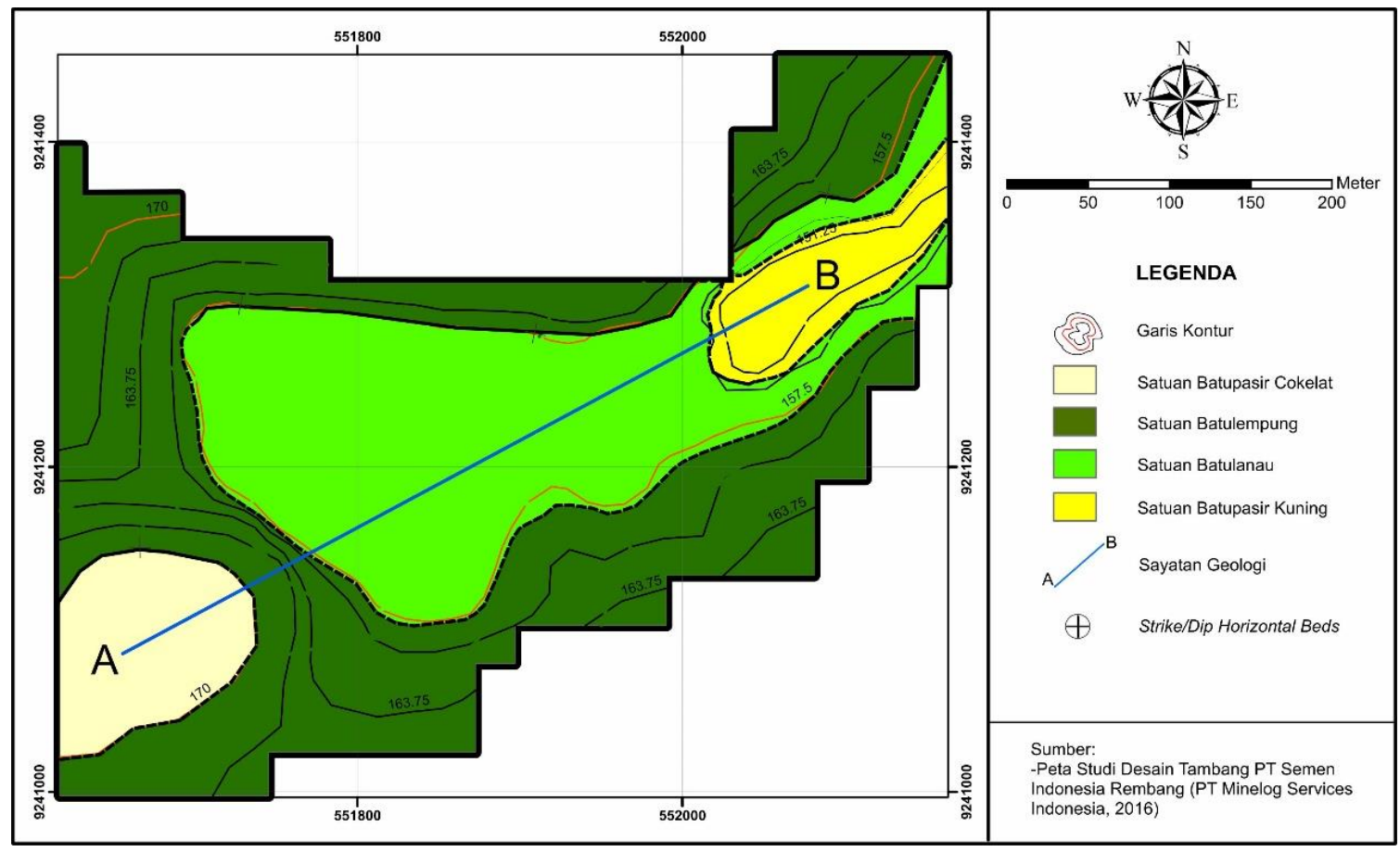

Gambar 4.2 Peta geologi daerah penelitian

\section{Persebaran Kadar Kimia}

Persebaran titik sampel dapat dilihat pada Gambar 4.14. Sebelum data kadar kimia diinterpolasi, terlebih dahulu mengatur variogram data yang dimiliki untuk meningkatkan akurasi prediksi interpolasi. Variogram dilakukan dengan membuat grafik sesuai dengan trend data yang dimiliki. Setelah membuat variogram, data diinterpolasi dengan metode kriging. Hasil interpolasi yang diperoleh dari metode kriging secara visual lebih baik dibandingkan dengan metode lainnya.

Hasil interpolasi kadar $\mathrm{Al} 2 \mathrm{O} 3$ dapat dilihat pada Gambar 4.15. Dari hasil interpolasi kadar Al2O3, dapat diketahui bahwa daerah yang berwarna merah hingga jingga memiliki komposisi $\mathrm{A} 12 \mathrm{O} 3$ yang rendah (low alumina) yaitu di bawah $16,5 \%$, sedangkan daerah yang berwarna jingga kekuningan hingga kuning keputihan memiliki komposisi $\mathrm{Al} 2 \mathrm{O} 3$ yang tinggi (high alumina) yaitu di atas 16,5\%.

Hasil interpolasi kadar $\mathrm{SiO} 2$ dapat dilihat pada Gambar 4.16. Dari hasil interpolasi kadar SiO2, dapat diketahui bahwa daerah yang berwarna hijau tua kebiruan hingga hijau memiliki kadar $\mathrm{SiO} 2$ yang rendah (low silica) yaitu di bawah $65 \%$, daerah yang berwarna hijau muda hingga kuning kejinggaan memiliki kadar $\mathrm{SiO} 2$ menengah (medium silica) yaitu di antara 65\% $70 \%$, dan daerah yang berwarna kuning
Tabel 4.1 Kisaran kadar kimia satuan batuan di daerah penelitian

\begin{tabular}{|c|c|c|c|}
\hline Litologi & $\begin{array}{c}\mathrm{Al}_{2} \mathbf{O}_{3} \\
(\%)\end{array}$ & $\begin{array}{l}\mathrm{SiO}_{2} \\
(\%)\end{array}$ & $\mathrm{SO}_{3}(\%)$ \\
\hline $\begin{array}{l}\text { Batupasir } \\
\text { Kuning }\end{array}$ & $12-16$ & $62-82$ & $0,5-1,5$ \\
\hline Batulanau & $18-22$ & $50-60$ & $1-3,25$ \\
\hline Batulempung & $18-26$ & $50-68$ & $0-1,5$ \\
\hline $\begin{array}{l}\text { Batupasir } \\
\text { Cokelat }\end{array}$ & $15-21$ & $60-80$ & $0-0,5$ \\
\hline
\end{tabular}

kejinggaan hingga merah memiliki kadar $\mathrm{SiO} 2$ yang tinggi (high silica) yaitu di atas $70 \%$.

Hasil interpolasi kadar SO3 dapat dilihat pada Gambar 4.17. Dari hasil interpolasi kadar SO3, dapat diketahui bahwa daerah yang berwarna putih hingga jingga kekuningan memiliki komposisi SO3 yang rendah (low sulphur) yaitu di bawah $1 \%$, daerah yang berwarna jingga kekuningan hingga jingga memiliki komposisi SO3 menengah (medium sulphur) yaitu di antara $1 \%-2,5 \%$, dan daerah yang berwarna jingga hingga merah memiliki kadar SO3 yang tinggi (high sulphur) yaitu di atas $2,5 \%$.

\section{PEMBAHASAN}

Kaitan Jenis Batuan Dengan Kadar Kimia

Distribusi kadar kimia masing-masing litologi, dilakukan overlay antara peta kontur kadar kimia dengan batas litologi yang hasilnya dapat dilihat 
pada Gambar 7, Gambar 8, dan Gambar 9. Rekapitulasi kisaran kadar kimia masing- masing satuan batuan dari hasil interpolasi kadar kimia dapat dilihat pada Tabel 4.1.

Batuan yang memiliki kadar Al2O3 tinggi dan paling dominan adalah batulempung, disusul dengan satuan batulanau, batupasir cokelat, dan batupasir kuning. Jika dilihat dari tekstur satuan batuan tersebut, semakin halus ukuran butirnya maka semakin besar kadar Al2O3. Komposisi $\mathrm{Al} 2 \mathrm{O} 3$ pada batuan sedimen silisiklastik berasal dari hasil pelapukan, erosi, dan transportasi batuan induk feldspatik. Akibat proses tersebut, mineral penyusun batuan induk feldspatik yang memiliki komposisi $\mathrm{Al} 2 \mathrm{O} 3$ menjadi berukuran sangat halus sehingga lebih banyak terakumulasi dan terendapkan pada daerah dengan energi pengendapan yang sangat rendah, oleh karena itu komposisi Al2O3 akan lebih banyak dijumpai pada batulempung yang memiliki ukuran butir sangat halus.

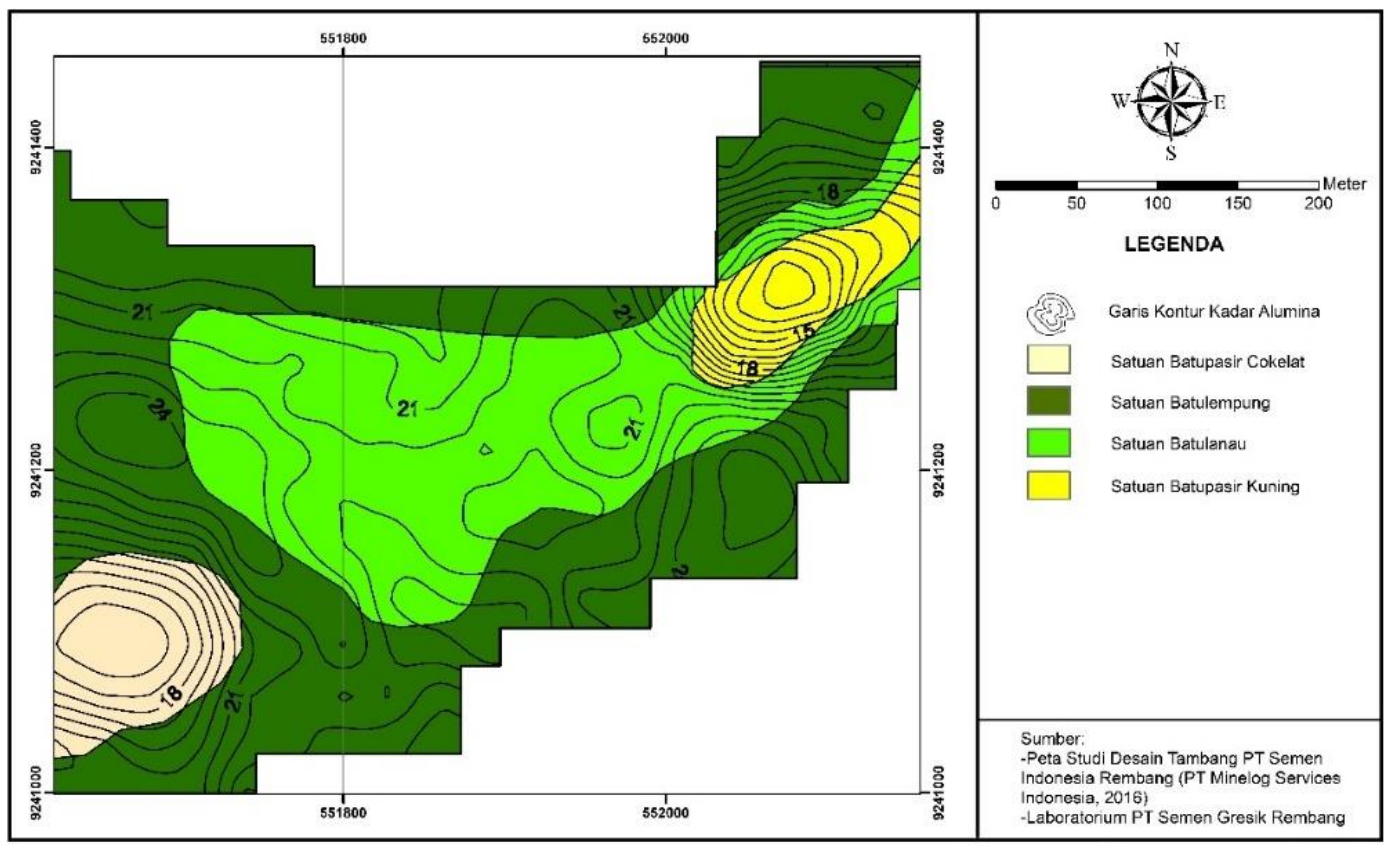

Gambar 7. Peta overlay kadar alumina dan batas litologi

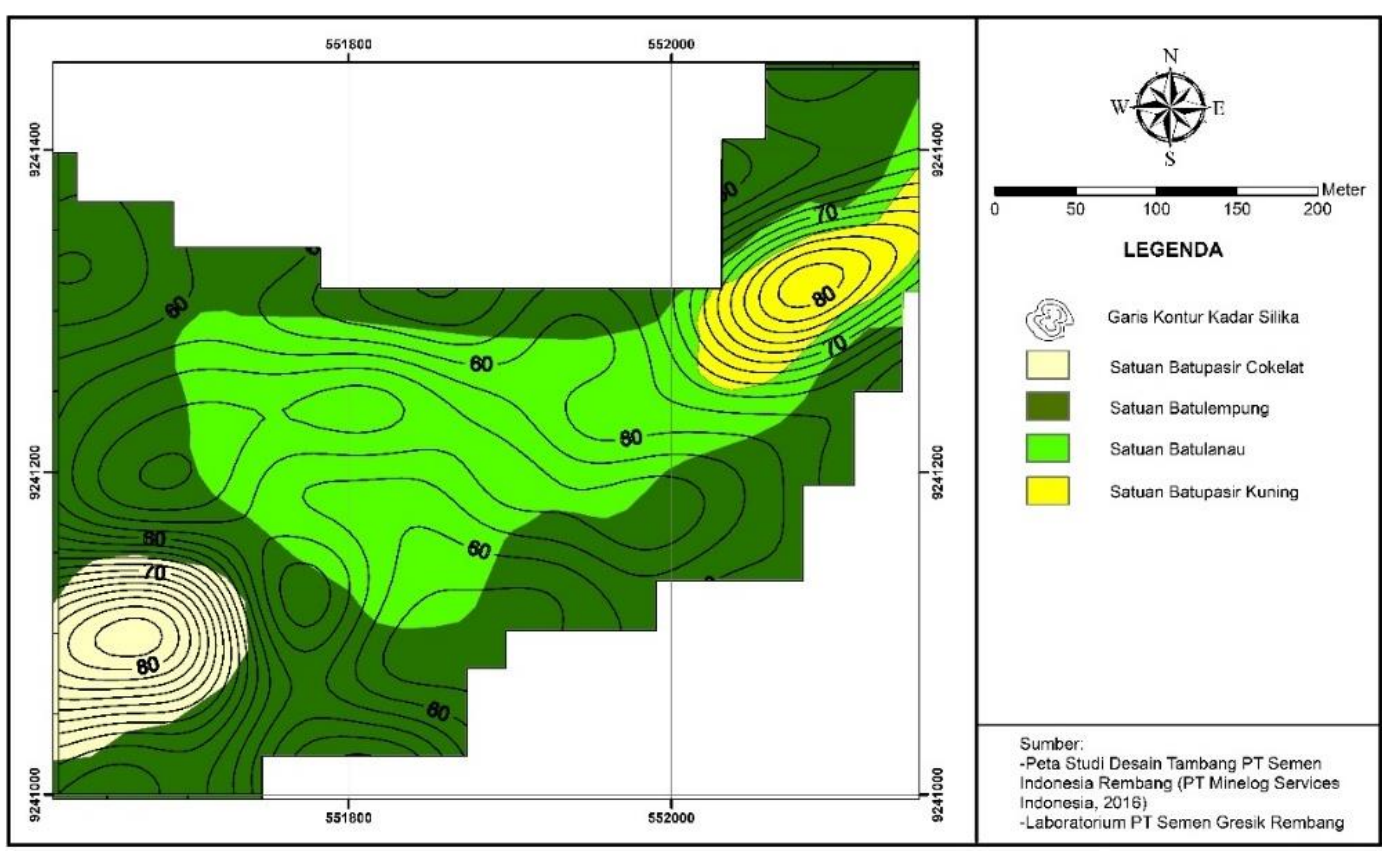

Gambar 8. Peta overlay kadar silika dan batas litologi 


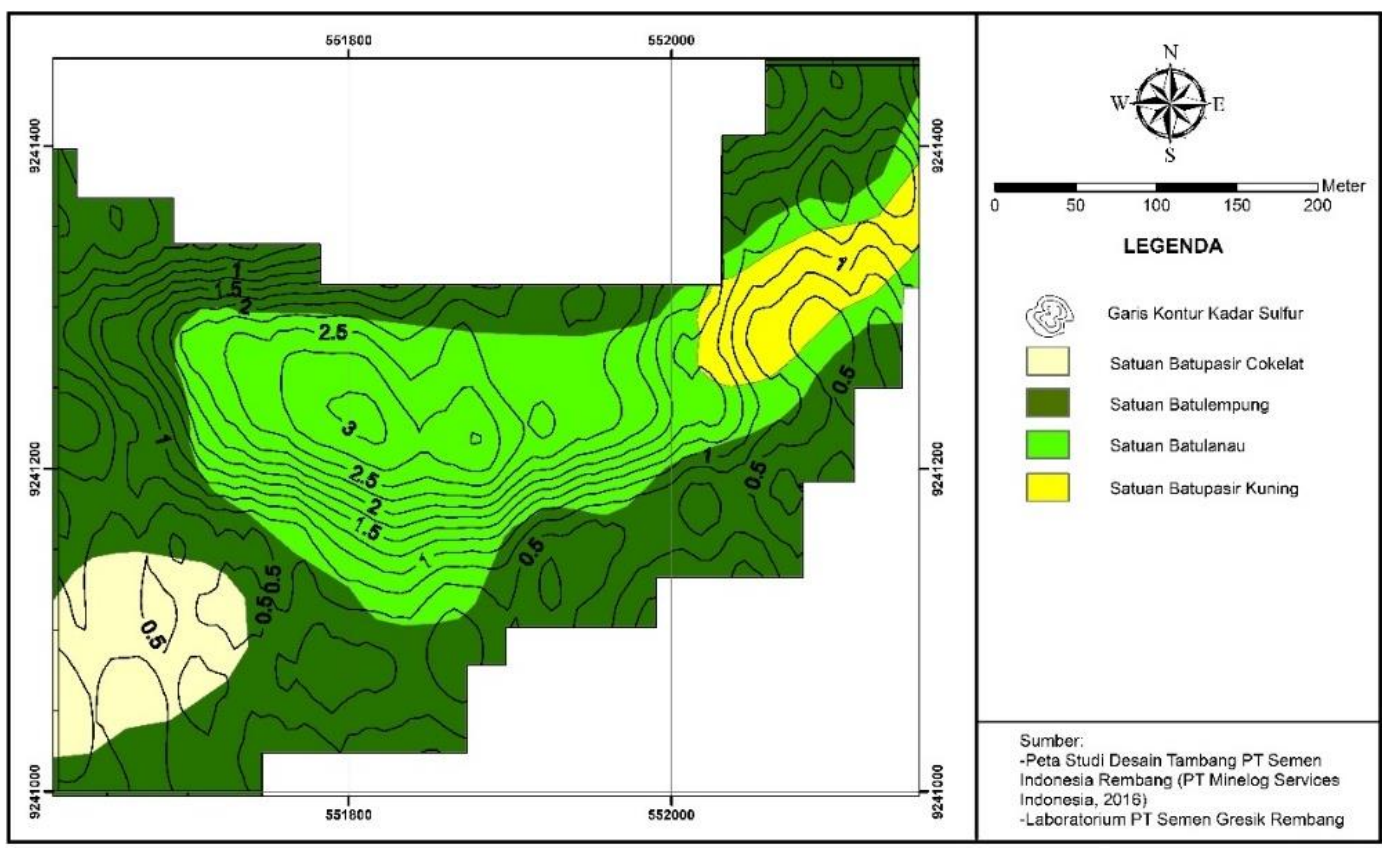

Gambar 9. Peta overlay kadar sulfur dan batas litologi

Batuan yang memiliki kadar $\mathrm{SiO} 2$ tinggi dan paling dominan adalah batupasir kuning, disusul dengan batupasir cokelat, batulanau dan batulempung. Komposisi $\mathrm{SiO} 2$ pada batuan sedimen silisiklastik berasal dari hasil pelapukan, erosi, dan transportasi mineral kuarsa yang terbentuk dari magma yang kaya akan silika. Mineral kuarsa merupakan mineral yang memiliki sifat paling stabil, dan paling banyak membentuk butiran pasir. Oleh karena itu, mineral kuarsa banyak ditemukan pada batuan sedimen berukuran pasir yang terakumulasi dan terendapkan pada daerah dengan energi pengendapan sedang.

Batuan yang memiliki kadar SO3 tinggi dan paling dominan adalah batulanau, disusul dengan batupasir kuning, batulempung, dan batupasir cokelat. Komposisi SO3 pada batuan sedimen silisiklastik berasal dari mineral pirit yang terbentuk akibat proses kimia di lingkungan pengendapan transisi hingga laut. Pada satuan batulanau yang ditemukan di lapangan terdapat komposisi mineral pirit baik yang terdiseminasi atau terkonsentrasi mengelilingi nodul oksida besi. Mineral pirit dapat terbentuk akibat senyawa sulfat yang banyak terdapat pada air laut bereaksi dengan ion besi yang dibawa oleh air sungai, dibantu oleh aktivitas bakteri. Dapat disimpulkan bahwa pada batuan sedimen silisiklastik yang terendapkan pada lingkungan transisi akan banyak memiliki komposisi SO3 yang dijumpai dalam bentuk mineral pirit.

\section{Kualitas Batuan Sebagai Bahan Campuran Semen}

Penentuan kualifikasi satuan batuan untuk menjadi bahan campuran semen mengacu kepada standar pada Tabel 3. Batupasir Kuning memiliki kadar $\mathrm{Al} 2 \mathrm{O} 3$ 12\%-16\%, $\mathrm{SiO} 2$ 62\%-82\%, dan SO3 0,5\%-1,5\%, sehingga tidak dapat digunakan sebagai bahan campuran semen. Satuan ini membutuhkan bahan korektif yang lebih banyak untuk dapat digunakan sebagai bahan campuran semen di tahap awal, dampaknya adalah peningkatan biaya produksi.

Batulanau memiliki kadar Al2O3 18\%-22\%, $\mathrm{SiO} 250 \%-60 \%$, dan SO3 1\%-3,25\%. sehingga tidak dapat digunakan sebagai bahan campuran semen karena memiliki kadar sulfur yang dominan melebihi batas yang ditentukan. Batulanau ini akan berpengaruh pada penurunan kinerja alat produksi terutama kiln, karena akan mempercepat pembentukan coating di seluruh sisinya.

Batulempung memiliki kadar Al2O3 18\%$26 \%$, SiO2 50\%-68\%, dan SO3 0\%-1,5\% yang dapat digunakan sebagai bahan campuran semen dengan memperhatikan kadar SiO2. Batulempung dengan kadar $\mathrm{SiO} 2$ kurang dari 65\% dapat dikoreksi dengan pasir kuarsa pada tahap pencampuran di Raw Mill. Batupasir Cokelat juga dapat digunakan sebagai bahan campuran semen karena memiliki kadar $\mathrm{Al} 2 \mathrm{O} 3$ $15 \%-21 \%, \mathrm{SiO} 260 \%-80 \%$, dan SO3 0\%-0,5\%. 


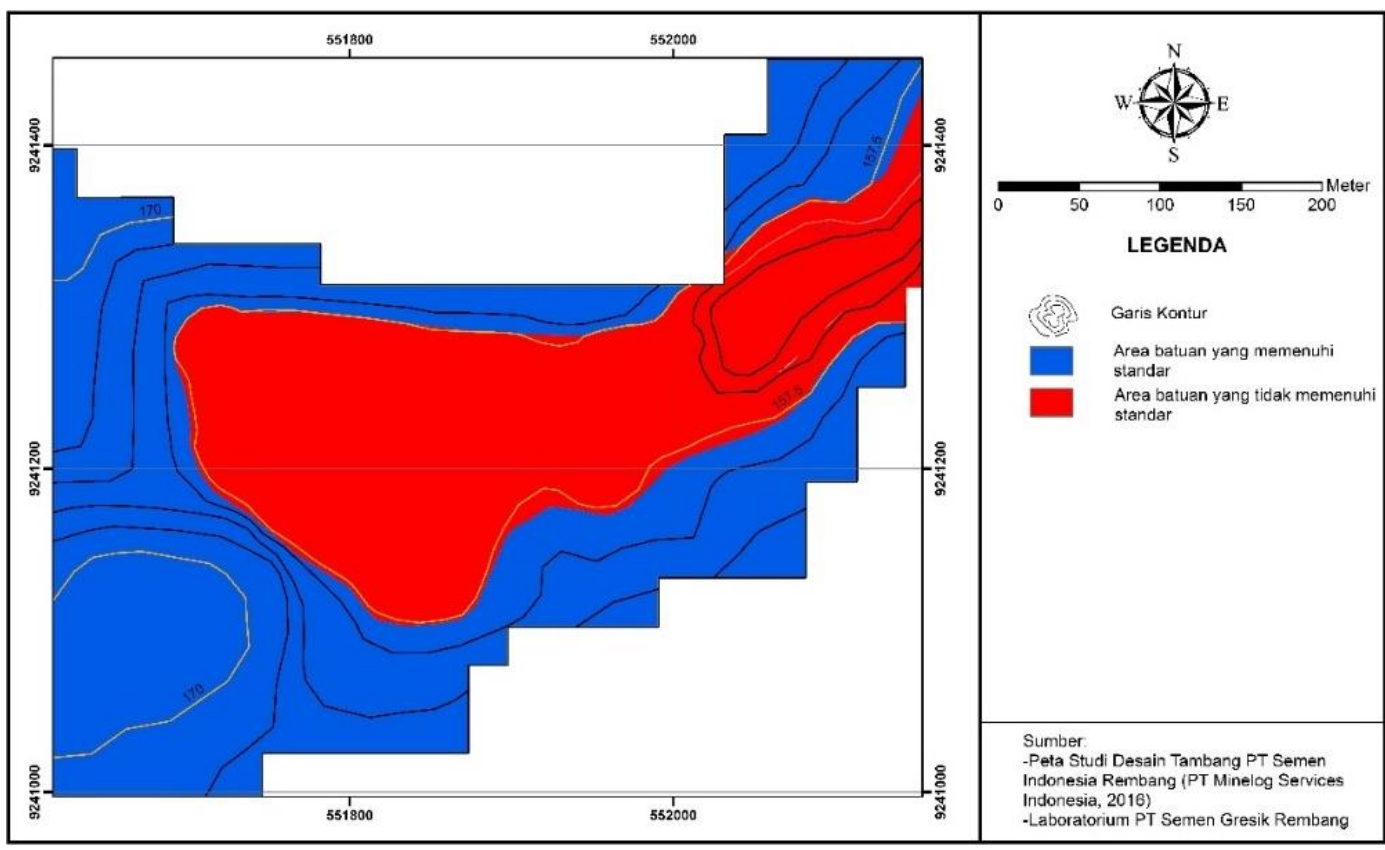

Gambar 4.21 Peta area kualitas litologi berdasarkan standar laboratorium PT Semen Gresik Kabupaten Rembang

Area persebaran litologi yang memenuhi dan tidak memenuhi standar laboratorium PT Semen Gresik Kabupaten Rembang dapat dilihat pada Gambar 4.21. Batupasir Kuning tidak dapat digunakan sebagai bahan campuran semen karena hanya kadar $\mathrm{SiO} 2$ yang tinggi, namun dapat digunakan sebagai bahan korektif semen, batulanau tidak dapat digunakan sebagai bahan campuran semen karena kadar SO3 melampaui batas maksimal, batulempung dapat digunakan sebagai bahan campuran semen dengan memperhatikan kadar $\mathrm{SiO} 2$, dan batupasir cokelat dapat digunakan sebagai bahan campuran semen.

\section{KESIMPULAN}

Daerah penelitian tersusun dari empat jenis satuan batuan di daerah penelitian yaitu Satuan Batupasir Kuning, Satuan Batulanau, Satuan Batulempung, dan Satuan Batupasir Cokelat. Persebaran kadar Al2O3 paling tinggi dijumpai di daerah yang tersusun oleh batulempung, kadar $\mathrm{SiO} 2$ paling tinggi dijumpai di daerah yang tersusun oleh batupasir kuning, dan kadar SO3 paling tinggi dijumpai di daerah yang tersusun oleh batulanau. Kadar Al2O3 banyak terdapat pada batulempung. Kadar $\mathrm{SiO} 2$ berasal dari mineral kuarsa dijumpai pada batupasir. Batupasir Cokelat dan Batulempung dapat digunakan sebagai bahan campuran semen. Batupasir Kuning tidak dapat digunakan sebagai bahan campuran semen karena kadar Al2O3 tidak memenuhi ketentuan, Batulanau tidak dapat digunakan sebagai bahan campuran semen karena kadar SO3 melebihi batas maksimum.

\section{UCAPAN TERIMA KASIH}

Penulis bermaksud mengucapkan terima kasih kepada PT Semen Indonesia (Persero) Tbk Rembang yang telah memberikan izin melakukan pengambilan data di IUP.

\section{DAFTAR PUSTAKA}

Abdillah, 2012. Studi Batuan Asal (Provenance) dan Diagenesis Batupasir Formasi Ngrayong Daerah Tempuran dan Sekitarnya, Kecamatan Medang, Kabupaten Blora, Jawa Tengah. Tidak dipublikasikan. Universitas Diponegoro: Semarang.

Aldieb, M. A. dan Ibrahim, H. G., 2010, Variation of Feed Chemical Composition and Its Effect on Clinker Formation - Simulation Process, San Fransisco: World Congress on Engineering and Computer Science Vol II

Badan Standarisasi Nasional, 2014, SNI 15-2049 Semen Portland, Jakarta: Badan Standarisasi Nasional

Badan Standarisasi Nasional, 2004, SNI 15-7064 Semen Portland Komposit, Jakarta: Badan Standarisasi Nasional

British Geological Survey, 2005, Cement Raw Materials, Nottingham: British Geological Survey

Darwis, 2018, Dasar-Dasar Mekanika Tanah, 
Yogyakarta: Pena Indis

Firmansyah, D. P. dan Dewi, K. I., 2014, Fasies Batugamping Formasi Paciran Berdasarkan Data Biostratigrafi, Sedimentologi, dan Petrografi, Pusat Studi Energi Universitas Padjadjaran: Bandung.

Kadar, D. dan Sudijono, 1993, Peta Geologi Lembar Rembang, Jawa, Bandung: Pusat Penelitian dan Pengembangan Geologi

Labahn, O., 1983, Cement Engineers Handbook, Bauverlag: Berlin.

Pardosi, N. dan Solihin, 2018, Geologi dan Studi Analisa Batuan Asal (Provenance) Batupasir Formasi Ngrayong Daerah Todanan dan Sekitarnya Kecamatan Todanan Kabupaten Blora Jawa Tengah. Universitas Pakuan: Bogor.
Pettijohn, F. J., 1975, Sedimentary Rocks $3^{\text {rd }}$ Edition, New York: Harper \& Row

PT Semen Gresik, 2019, Kadar Kualitas Kimia Tanah Liat dan Proses Industri PT Semen Gresik, Rembang

Shetty, 2000, Concrete Technology. S. Chand \& Company Ltd.: New Delhi. 